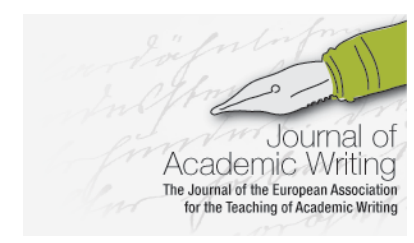

Journal of Academic Writing

Vol. 7 No 1 Summer 2017, pages 27-42

http://dx.doi.org/10.18552/joaw.v7i1.214

\title{
Revision Processes in First Language and Foreign Language Writing: Differences and Similarities in the Success of Revision Processes
}

\author{
Esther Odilia Breuer \\ University of Cologne, Germany
}

\begin{abstract}
Writing academic texts in one's native language (L1) and - even more - in a foreign language (FL) places high cognitive demands on students. In order to cope with these demands, writers should learn to adapt their writing methods flexibly to their tasks, depending on the language and the genre they are writing in. Crucial aspects here are the methods of revising because the need for linguistic revision will be higher in the FL text than in the L1 text; at the same time, it should not be the main or only focus of the revision process. In order to analyse the differences in L1 and FL revision, a study was set up in which ten L1 German students wrote academic essays in German and in English. The production process was protocolled with the help of keylogging, so that the revising processes could be analysed. The results show that the participants revised similarly in both the L1 and the FL. They focussed on the same aspects (content, typing mistakes, and language errors that were not L1 related). At the same time, there are differences in finer grades. These differences in revision do not seem to be a conscious decision, however, but are rather the result of the higher cognitive demands in FL academic writing and the lower degree of language knowledge. Additionally, the analysis of the final FL texts showed that most of the errors that were not corrected were L1 induced. When one looks at the revisions, however, one sees that hardly any revisions were made in these aspects: the L1 influence went more or less unnoticed. For writing pedagogy, this means that one has to put a higher focus on revision strategies during teaching, in order to give students the tools to write successfully in L1 and in FL, and to motivate them in enhancing their papers.
\end{abstract}

\section{Introduction}

Idea generation, planning, translation/formulation, execution and revising are the core processes in writing (e.g. Flower and Hayes 1980, Hayes 2008). These processes do not work one after the other but they are interrelated and in many cases work in parallel. Research has shown that this works differently in the first language (L1) compared to the foreign language (FL) or second language (L2) (e.g. Chenoweth and Hayes 2001). How these processes and methods differ and whether one can manipulate the revision processes by explicitly activating the language faculties (Jackendoff 2003) by using different planning methods was tested in a study in 2012 (Breuer 2015a). The goal of the study was to see whether different planning methods worked better (in general or in one or in the other language) in order to supply L2 and FL writers with tools for dealing with the high demands of FL academic writing. This article presents the results of the study with respect to one of the core writing activities related to text quality, the revision process. 


\section{The revision process}

The revision process is a complex and demanding task, but it is crucial to producing a text that conveys meaning in a way that is appropriate for the target audience in the academic setting. In revisions, writers read, edit and evaluate the text they have produced with respect to 'linguistic, semantic and pragmatic peculiarities of the writing goal' (Alamargot and Chanquoy 2001: 5). If the evaluation is negative, writers undergo a new process of planning and formulating (Hayes et al. 1987). This process of evaluating and deciding on alternatives is an active one: writers decide on the evaluation criteria that are applied in the text and judge whether and in which respects the text they have written fulfils these criteria. Editing can be executed in different depths. One can concentrate on localised error revision (e.g. spelling and punctuation), address global problems (e.g. the text's structure), or focus on aspects between these two extremes (Kellogg 1996).

Revision is not restricted to the written text, but already takes place before and after execution; that is, it does not always involve reading. One can edit ideas, text organisation, text goals, inner speech, etc. before execution. In this way, reviewing can interrupt any writing process and cause the writer to 'jump' through the different sub-processes of writing (Flower and Hayes 1980). It can also lead to new idea generation, in that the reading of the text triggers other entries in long-term memory (van den Bergh and Rijlaarsdam 1999, 2008, and Galbraith 1999, 2009). Revision can thus become 'a springboard to further translating or with an eye to systematically evaluating and/or revising the text' (Flower and Hayes 1981: 374). Often, the result is new planning, formulating, and new revising.

However, this may work differently in L1 and FL writing. Chenoweth and Hayes (2001) found that in FL writing, editing during the process of composition was less fruitful than editing after composition was complete. This may be attributable to the higher demands made on cognitive resources by writing in the $\mathrm{FL}$, which means it is more efficient to try to undertake fewer processes in parallel (Hayes 2009).

There is an attitude which suggests the more the writer revises the text the better it will be (e.g. Britton 1996), but this must be recognised as a generalisation requiring qualification and further analysis. Novice writers, less skilled or insecure writers, and in many cases FL writers, may also spend a lot of time on revision, but they tend to concentrate exclusively on revising spelling or wording (Becker 2006); that is, they often confine revisions 'to a cosmetic level of little more than proofreading' (Bereiter and Scardamalia 1987: 22). They neglect structure or cohesion, whether it is because they still lack the necessary diagnostic skills (Bereiter and Scardamalia 1983, Breetvelt, van den Bergh and Rijlaarsdam 1994, Flower and Hayes 1981, Hayes 1996, and Pritchard and Honeycutt 2008), or because the demands on working memory reduce their capacity to concentrate on problem finding (Becker 2006, McCutchen 2011, and Phillips and Baddeley 1989). Additionally, text revision does sometimes not lead to an improvement in the text, indicating that the writers' cognitive abilities are not adequate to the writing task and that they are struggling to find strategies to compensate for these deficiencies (Rijlaarsdam, Couzijn and van den Bergh 2004). Only for practised writers can revision function as another opportunity for discovering new ideas and structures, using the already written text as a discussant.

One group that does not fit the category of "practised writers" is students; they are often criticised for their written texts, which are neither linguistically nor structurally adequate. The reason for this can be that they see revision as a 'punitive' (Becker 2006: 25) process rather than an opportunity to communicate with their texts and enhance them. As a result, they tend to set the focus of revision on local rather than global aspects, revising exclusively linguistic and/or orthographic errors that they find in the texts. This is even more so for L2 or FL writers. For these reasons, a study was undertaken to examine the revision processes of students, in order to determine whether there are distinct points on which to focus teaching how to vary revision processes under different writing conditions. The study also examined whether different planning conditions (discussed below) might influence writing and revising behaviour, which could be applied in the teaching of academic classes. 


\section{The study}

Ten German students of English philology in the teacher training programme or in Master's programmes with two topics (English + one other subject) participated in the study. Seven of them were female, three were male, reflecting the distribution among the sexes at our university. They all volunteered for participation in the study, and received detailed feedback on their written texts and their writing processes, as well as compensation for time spent on the study. They were on average in the 8th semester and had all attended at least one obligatory class on English essay writing in their student curriculum. In these classes, a rather strict plan for essay writing is taught: introduction, main part (pro argument, contra argument, synthesis), and conclusion. This taught structure is of course not always applicable depending on the topic, but it helps German students to move away from the nonlinear German approach to academic writing, and toward the strictly linear English style. None of them had attended a class on German academic writing, which are optional at Cologne University.

In the study the participants wrote four academic essays, two in their L1 and two in their FL. The topics for the essays were drawn from areas in which every student had a certain amount of background knowledge, and in which they could take a position. Additionally, the participants wrote a simple English text (SE) in order to test their general FL writing competencies.

What is unique about the study is that the participants used different planning methods for one of the essays in each language: one L1 and one FL essay was planned with the help of notetaking (L1N and FLN). The participants wrote down the keywords that they found relevant for the essay and numbered their notes in the order in which they wanted to take up the topics. The other essays (L1F and FLF) were planned with the help of freewriting (Elbow 1973). The students wrote the plans without pausing and (if possible) without any revisions for five minutes. It was proposed that by activating the FL linguistic structures via freewriting, the influence of the L1 on FL writing could be reduced and that the participants could write more fluently without having to stop and think about words, sentence structure, orthography and other stylistic and linguistic matters. This would also give the participants a better opportunity to focus on different aspects during the writing process, for example on an effective revision strategy.

The writing processes were logged with the help of Translog, a keylogging tool which records keystrokes and mouse movements. The advantage of this method is that, although the writing processes are taped and can be analysed afterwards, the writers do not feel monitored and do not have to change anything in their writing performance, as compared to, for example, using the think-aloud recording method. Working with the logs (tapes as well as statistical files created by the programme), one is able to analyse the fluency of the execution processes and the revision processes participants applied during execution.

In order to analyse the results, the processes of revision were categorised. The categories were based on errors found in the final texts; that is, they are based on writing problems which would have required more revisions. More than sixty per cent of the errors were different kinds of node-switches (Breuer 2015a). Node-switches are defined as L1-induced errors, for example, writing an English noun with a capital letter as required in German orthography. Other error categories were code-switches, typing mistakes, miscellaneous (linguistic errors that were not induced by the other language) and errors in content (see Figure 1). 


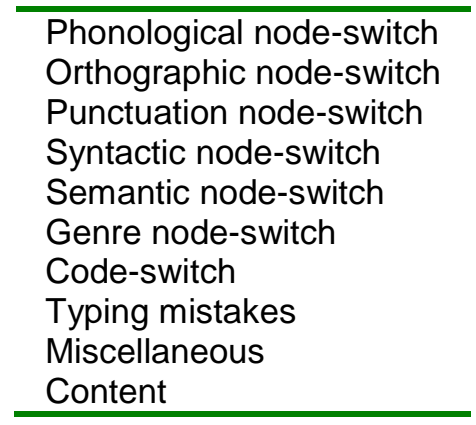

Figure 1. Revision categories.

Some types of errors and revisions were so frequent that they were subcategorised. Content, miscellaneous, and orthographic node-switches were the three categories, beside typing mistakes, in which most revising occurred. The following table presents the subcategories in these three categories:

Table 1. Subcategories of revision categories.

\begin{tabular}{|c|c|c|}
\hline Content & Miscellaneous & Orthographic node-switches \\
\hline $\begin{array}{l}\text { Information (adding extra } \\
\text { information, changing } \\
\text { the information provided) }\end{array}$ & $\begin{array}{l}\text { Grammar (errors in grammar } \\
\text { that are not rooted in the } L 1 \text { ) }\end{array}$ & $\begin{array}{l}\text { L1 rule (e.g. ment instead of } \\
\text { meant because of adjusting the } \\
\text { spelling to the pronunciation) }\end{array}$ \\
\hline $\begin{array}{l}\text { Wording (better/more } \\
\text { fitting expression) }\end{array}$ & $\begin{array}{l}\text { Orthography (errors in } \\
\text { orthography that are not } \\
\text { rooted in the L1) }\end{array}$ & $\begin{array}{l}\text { Capital letter (e.g. He is a } \\
\text { wealthy Man.) }\end{array}$ \\
\hline $\begin{array}{l}\text { Sentence structure } \\
\text { (putting the central } \\
\text { aspects to a more central } \\
\text { place in the sentence, } \\
\text { e.q. main clause) }\end{array}$ & $\begin{array}{l}\text { Punctuation (errors in } \\
\text { punctuation that are not } \\
\text { rooted in the L1) }\end{array}$ & $\begin{array}{l}\text { L1 way (garanties instead of } \\
\text { guaranties as in the German } \\
\text { word Garantien) }\end{array}$ \\
\hline $\begin{array}{l}\text { Text structure (putting } \\
\text { information at another } \\
\text { place) }\end{array}$ & $\begin{array}{l}\text { Other }^{1} \text { (e.g. writing } \\
\text { something down, deleting it } \\
\text { and writing down exactly the } \\
\text { same) }\end{array}$ & $\begin{array}{l}\text { One word (e.g. kitchentable) } \\
\begin{array}{l}\text { Apostrophe (e.g. This mans } \\
\text { joke.) }\end{array}\end{array}$ \\
\hline $\begin{array}{l}\text { Numbering (changing } \\
\text { the numbering in the } \\
\text { plans) }\end{array}$ & & $\begin{array}{l}\text { Other (e.g. writing a word that is } \\
\text { phonologically related to the } \\
\text { intended word, and in which the } \\
\text { spelling would relate better to } \\
\text { German orthographic system } \\
\text { as in bed instead of bad) }\end{array}$ \\
\hline
\end{tabular}

The following results present how revision differs in the different languages and under the different planning conditions. The average number of revisions, the number of characters executed without revisions, and the types of revisions made are analysed. The results also examine which kinds of revisions were performed in $p$-bursts (revisions performed after a pause, in contrast to $r$-bursts, which are performed without a pause before executing the revision) and how these revisions affected fluency.

1 'Other' is used to distinguish these subcategories of infrequent revisions from 'miscellaneous' as a top category type. 
It was assumed that, due to the different cognitive demands, the participants would concentrate on different aspects under the different task conditions. It was also assumed that the participants would focus more on linguistic aspects in FL writing than in L1 writing because the analysis of the formulating process and of the final texts showed that the participants worked more fluently in the L1 but they also left a high number of serious linguistic errors uncorrected (Breuer 2015a). Such a pattern as this could be used in giving feedback to the students, based not solely on the written text, but rather on the writing processes which need more attention in order to create a better essay.

\section{Results}

\section{Analysis of revisions in the overall text production}

Table 2 displays an overview of the numbers of revisions made on average in the different assignments.

Table 2. Mean number of revisions in the different task conditions.

\begin{tabular}{lrrrrr}
\hline & SE & L1N & FLN & L1F & FLF \\
\hline Total number of revisions & 88.90 & 168.50 & 156.40 & 192.00 & 165.90 \\
\hline
\end{tabular}

The number of revisions differs distinctly between $\mathrm{L} 1$ and $\mathrm{FL}$ and between the different task types. The lowest number of revisions is located in the SE, the highest in the L1F. However, the picture changes when one takes into account the number of characters the writers produced during the writing process $^{2}$ (Table 3 ):

Table 3. Mean number of characters without revision.

\begin{tabular}{lrrrrr}
\hline & SE & L1N & FLN & L1F & FLF \\
\hline $\begin{array}{l}\text { Number of characters without } \\
\text { revision }\end{array}$ & 32.5 & 32.51 & 28.84 & 34.04 & 32.5 \\
\hline
\end{tabular}

The writers produced more text without revision in the L1F (34.04 characters) than in the SE, the L1N, and the FLF in which the numbers of revision are basically the same. In the FLN, the writers felt the greatest necessity to revise (28.84).

Under all conditions, the highest number of revisions is located in typing mistakes: (SE: $57.28 \%$ of the revisions, L1N: 53.5\%, FLN 53.77\%, L1F 60.43\%, FLF 54.38\%, Fig. 2). In the L1F and in the SE, the proportionate revision of typing mistakes was distinctly higher than in the notetaking conditions or in the FLF condition. In the L1 as well as in the FL, these typing mistake revisions often occurred in executing foreign words (e.g. rheoric instead of rhetoric), and in many cases, the participants were not able to correct these mistakes on the first attempt, needing second or third attempts.

\footnotetext{
2 Since German has a high capacity for creating compounds of more than two words (Wohnzimmerfenster vs. living room window) a comparison of the number of words would have been misleading. The comparison of the numbers of characters was seen as the best compromise.
} 

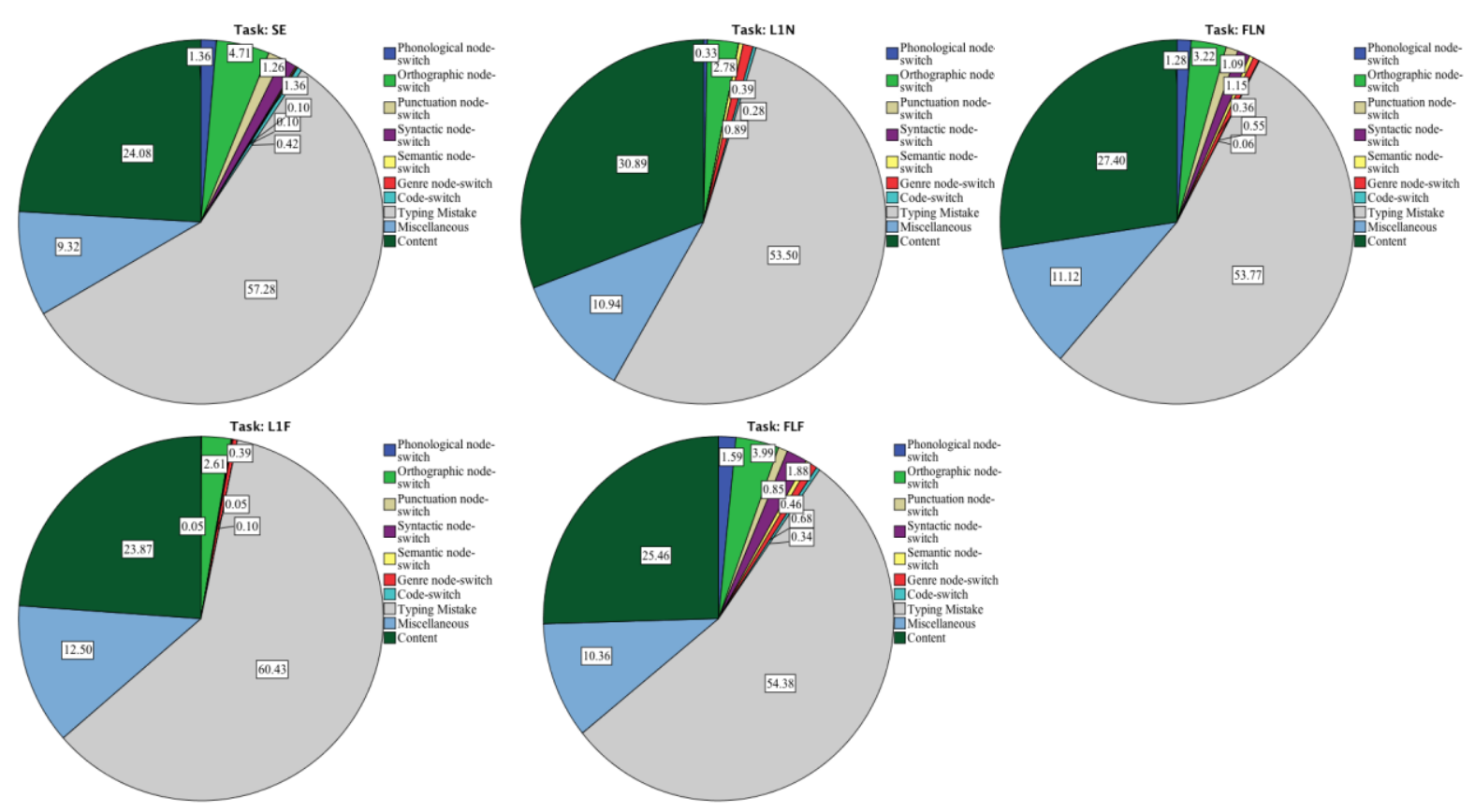

Figure 2. Distribution of revisions in the different categories.

Other categories in which revisions were executed to a noteworthy extent are in content (between $23.87 \%$ in the L1F (lowest rate) and $30.89 \%$ in the L1N (highest rate)), in miscellaneous (between $9.32 \%$ in the SE and $12.5 \%$ in the L1F) and in orthographic nodeswitches (between $2.61 \%$ in the $\mathrm{L} 1 \mathrm{~F}$ and $4.71 \%$ in the SE). The revisions in the subcategories of these categories are analysed in more detail below.

In the remaining categories, the number of revisions was lower than two per cent.

\section{Revision of content}

Figure 3 provides an overview of the distributions of the revisions in the subcategories of content in the different tasks. If one excludes numbering, which could not take place under the SE or freewriting conditions, the overall patterns are the same in all conditions. Information is always the most important subcategory, followed by wording, sentence structure and text structure. In the note-taking conditions, revisions of numbering are more relevant than revisions of text structure. 

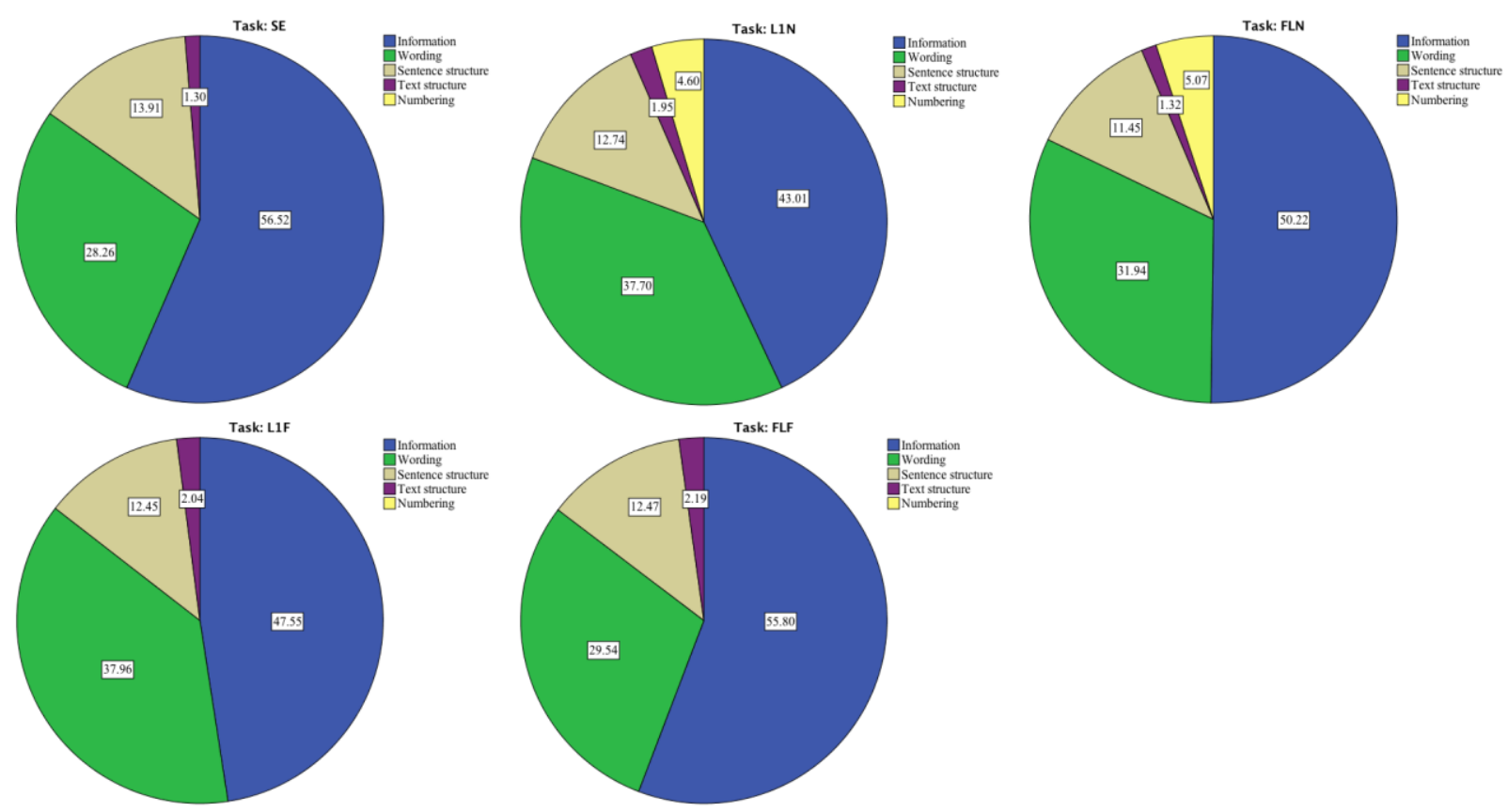

Figure 3. Distribution of revisions in content.

Although the majority of revisions in content were made in the subcategory information in all text types, there are distinct differences in the proportions. In FLF writing and in SE writing, revisions of content account for more than fifty per cent (FLF: $55.80 \%$, SE: $56.62 \%$ ). In the FLN, the subcategory information comprises $50.22 \%$ of the revisions, in the $\mathrm{L} 1 \mathrm{~N} 43.01 \%$, and in the $\mathrm{L} 1 \mathrm{~F} 47.55 \%$. In the $\mathrm{FL}$, information in both conditions is more dominant than in the L1. Even if one excludes numbering from the analysis, the results show that the revision of information is higher in the freewriting-condition than in the note-taking condition, and that the percentage of these revisions is distinctly higher in the SE than in the academic essays.

In contrast to information, the proportions of revisions in wording are higher in the $\mathrm{L} 1$ than in the FL: L1N: $37.7 \%$ (39.52\% if numbering is excluded); L1F: $37.96 \%$; FLN: $31.94 \%$ (33.64\% if numbering is excluded); and FLF $29.54 \%$. It was lowest in the SE with $28.26 \%$. The languageinternal differences between the planning conditions are low, although if one excludes numbering, the difference in the FL becomes more distinct.

There are no distinct differences between the revisions of sentence structure in the task conditions: SE: 13.91\%; L1N: 12.74\%; FLN: 11.45\%; L1F: 12.45\%; and FLF: 12.47\%. These revisions were often the consequence of added information which had to be syntactically integrated into the text.

Text structure was very rarely revised in the writing process. In the $L 1$, the results are basically the same (L1N: $1.95 \%$, L1F: $2.04 \%)$, whereas in the FL, the difference between the planning conditions is slightly bigger: $1.32 \%$ in the FLN, and $2.19 \%$ in the FLF. In the SE the participants revised roughly as much as in the FLN: $1.30 \%$.

\section{Revisions in miscellaneous}

Figure 4 demonstrates that for all texts the majority of revisions in the category miscellaneous were made in the subcategory others. In the L1N, the proportion is lowest $(59.09 \%)$. It is highest in the SE (76.4\%). In the L1 academic essays, the proportion of the subcategory others is lower in both task-conditions than in the FL academic essays. In the L1N the proportion is lowest $(59.08 \%$, L1F: $62.45 \%)$. In contrast to the L1, the FLF shows slightly less revisions in the subcategory others $(65.56 \%)$ than the FLN $(68.31 \%)$. 

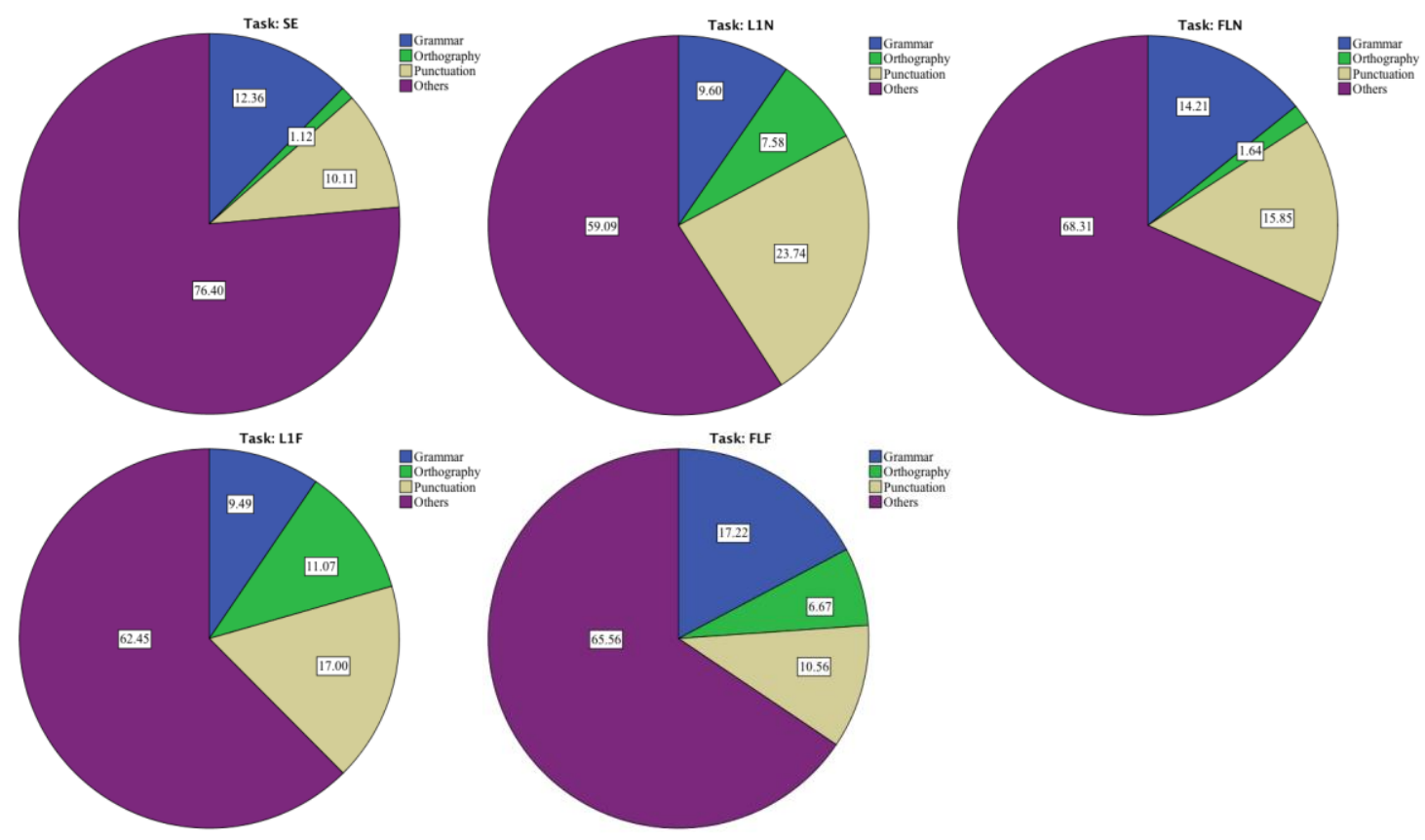

Figure 4. Distribution of revisions in miscellaneous.

Revisions in grammar were also executed to a large extent in the subcategory others. Proportionally more revisions were executed in the FL conditions (SE: $12.36 \%$, FLN: $14.21 \%$, FLF: $17.22 \%$ ), whereas in the L1 the proportion is lower than $10 \%$. In the latter case and in the FLN, revisions of punctuation were most dominant after the revisions of others $(\mathrm{L} 1 \mathrm{~N}: 23.74 \%$, FLN: 15.85, L1F: 17\%). The results for the SE and the FLF are nearly identical at $10.11 \%$ and $10.56 \%$. Hardly any orthographic revisions were executed in the SE $(1.12 \%)$ and in the L1N (1.64\%); more of these revisions were made in the L1N (7.58\%) and in the FLF (6.67\%), and most in the L1F (11.07\%).

\section{Revision in orthographic node-switch}

Orthographic node-switch is the only category in which L1-induced errors in the FL texts or FLinduced errors in the L1 texts were revised to a remarkable extent. They occupy the fourth place in the 'ranking' of revisions. In the SE, $4.71 \%$ of the revisions were executed in this category; in the L1N, it was 2.78\%, in the FLN 3.22\%, in the L1F 2.61\%, and in the FLF 3.99\%.

It is remarkable that the percentage of orthographic node-switch revisions from the FL to the L1 is above $2.5 \%$. These node-switches were almost exclusively located in the subcategory capital letters (L1N: 84\%; L1F: 82.69\%; see Figure 5). The writers had to correct the spelling of nouns from lower case letters to capital letters. Stating that in these cases "real" node-switches take place is ambiguous because of the fashion of exclusively using lower-case letters in some genres of current fictional texts, and even more so in writing in the internet or in writing SMS (Schübel 2009). It is a kind of "public orthographic node-switch", which is unwelcome for scholarly writing in the L1 academic community, however. 

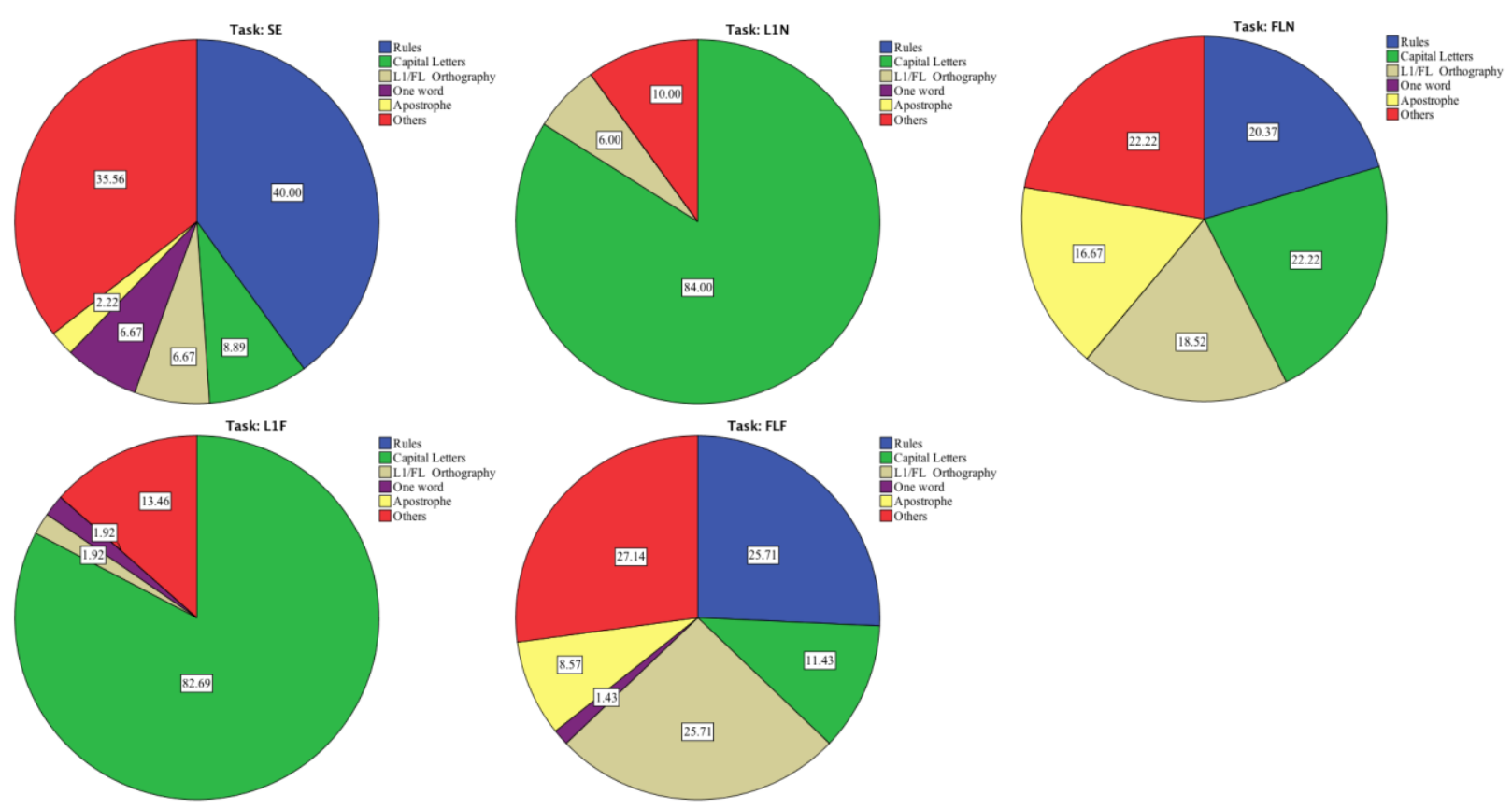

Figure 5. Distribution of revisions in orthographic node-switch.

Another FL to L1 orthographic node-switch revision was the carrying over of English orthography to a word that exists in English as well as in German. This type of revision was higher in the $\operatorname{L1N}(6.00 \%)$ than in the L1F $(1.92 \%)$. One participant made a node-switch revision in the subcategory one word, when she started to write Bolognaprozess in two words, like it is done in English (Bologna Process) and corrected it later. This term seems to have been problematic for many participants, because a high number wrote Bologna Prozess in their essays without correcting it.

Another relevant subcategory in orthographic node-switch revisions in the L1 was others, which was also relevant in the FL texts. This subcategory will be examined more closely below.

In the $\mathrm{FL}$ texts, the orthographic node-switch revisions took place in the subcategories $L 1$ rules (SE: 40\%, FLN: 20.37\%, FLF: 25.71\%), capital letters (SE: 8.89\%, FLN: 22.22\%, FLF: 11.43\%), L1 orthography (SE: $6.67 \%$, FLN: $18.52 \%$, and FLF: $25.71 \%$ ), one word (SE: $6.67 \%$, FLN: 0\%, FLF: $1.43 \%$ ), apostrophe (SE: $2.22 \%$, FLN: $16.67 \%$, FLF: $8.57 \%$ ) and others (SE: $35.56 \%$, FLN: $22.22 \%$, FLF: 27.14\%). The distribution in the subcategories in the SE is distinctly different from the distributions in the academic texts. Here, the two categories $L 1$ rules and others comprise more than $75 \%$ of total revisions. Capital letters, L1 orthography and apostrophe, which are relatively important in the academic essays, are only of marginal relevance in the SE.

In all FL texts, the majority of errors revised in the subcategory $L 1$ rules were initiated by the underlying intention of German orthography to adapt spelling to (high-standard) pronunciation, and to adjust the orthography of words that belong to one family. Many of the orthographic errors also related to the German phonological rule that vowels at the end of a syllable are unvoiced. An example of these kinds of node-switches is live instead of life.

In the FL academic essays, capital letters and apostrophe are also relevant subcategories. In the FLN the proportion of revisions in capital letters is distinctly higher than in the FLF, being the most important subcategory in revisions beside the revisions in others.

Most of the revisions in the subcategory others (in the L1 as well as in the FL) involved participants executing phonological or orthographic associations to the intended words, for example I thing instead of I think or shop instead of shoot. In the L1F, the proportion is $3.36 \%$ higher than in the L1N, in the FLF it is $4.92 \%$ higher than in the FLN. In the SE, it is $23.68 \%$ 
higher than in the FLF.

Revisions in $\mathrm{p}$-bursts

The analysis of the keylog protocols showed that in the SE and in the FLN more $p$-bursts occurred than $r$-bursts, and the proportion of $r$-bursts rose in the freewriting condition, in the L1 as well as in the FL (Breuer 2015a). Furthermore, one could see that most of the pauses were not used for revising but for planning the text. The following discussion analyses the distribution of revisions in the different categories which were made after pausing (Table 4), as well as the distribution of revisions after which the participants paused (Table 5).

Table 4. Proportion of revisions after pauses to revisions in total.

\begin{tabular}{lrrrrr}
\hline$\%$ & SE & L1N & FLN & L1F & FLF \\
\hline Phonological node-switch & 0.00 & 0.00 & 9.52 & 100.00 & 7.14 \\
Orthographic node-switch & 8.89 & 16.00 & 16.98 & 7.55 & 12.86 \\
Punctuation node-switch & 25.00 & - & 33.33 & 50.00 & 40.00 \\
Syntactic node-switch & 38.46 & - & 47.37 & - & 42.42 \\
Semantic node-switch & 0.00 & 14.29 & 50.00 & 0.00 & 37.50 \\
Genre node-switch & 0.00 & 43.75 & 77.78 & 37.50 & 33.33 \\
Code-switch & 0.00 & 40.00 & 100.00 & - & 33.33 \\
Typing mistakes & 8.23 & 10.80 & 11.30 & 8.31 & 8.90 \\
Miscellaneous & 29.21 & 38.07 & 35.52 & 23.62 & 28.02 \\
Content & 40.87 & 46.76 & 54.99 & 39.18 & 46.53 \\
\hline
\end{tabular}

Table 4 illustrates that in most of the categories only the minority of error corrections and revisions were executed after $p$-bursts. The proportion of revisions after pausing is lowest in the category of typing mistakes, in orthographic node-switch, and in phonological node-switch (in the L1F only one phonological node-switch revision occurred, which makes the $100 \%$ misleading). That is, more localised errors were in most cases detected and corrected immediately. In the L1, this process worked slightly more efficiently than in the FL (although the results are close); in the freewriting condition the immediate revision of these types of errors worked distinctly better than in the note-taking condition.

Revisions in other categories more often needed time before they were executed or before the errors or weaknesses were detected. The writers paused before revising in more than fifty per cent of the cases in the FLN in some categories. As was expected, revisions in content are the ones that were most demanding in all conditions.

Genre node-switch revision, that is the adjustment of the text from Teutonic to Saxonic style (Galtung 1981), and code-switch revision, were most demanding in the FLN as well content and semantic node-switching. In both categories, the participants needed to pause before revising in over $50 \%$ of the cases. The participants were more efficient in the FLF condition than in the FLN condition in directly revising genre node-switches, semantic node-switches, syntactic node-switches and miscellaneous. The writers were also slightly more efficient in detecting node-switches between L1 and FL syntactic structures after planning by freewriting.

In the L1 academic essays, most linguistic error revisions were categorized as miscellaneous. As in the FL, the revision of linguistic errors without former pausing was higher in the L1F. However, this did not have a positive effect on the errors in the final texts (Breuer 2015a).

The only error category that was less efficiently detected in the freewriting condition in both languages is punctuation node-switch. Here, the writers needed pauses more often before revising than in the note-taking condition. 
Table 5 shows not only that the need for revisions was detected without pausing in most cases, but that the revisions were not very obstructive for the writing processes. Only in the minority of cases did participants make pauses after revising. They were able to keep the train of thought or the plan for the following passage in mind in most cases, while they were completing the revising processes.

In some categories, only in one language or in one condition, there were cases of pausing after the revision. These occurred with semantic node-switches in the L1N and after genre nodeswitch revisions as well as code-switch revisions in the FLF. Revisions of orthographic, punctuation, and syntactic node-switches, which were followed by pauses, occurred exclusively in the FL.

Table 5. Proportion of pausing after revisions to revisions in total.

\begin{tabular}{|c|c|c|c|c|c|c|}
\hline & $\%$ & SE & L1N & FLN & L1F & FLF \\
\hline Phonological node-switch & & 0.00 & 0.00 & 0.00 & 0.00 & 0.00 \\
\hline Orthographic node-switch & & 0.00 & 0.00 & 1.89 & 0.00 & 1.43 \\
\hline Punctuation node-switch & & 8.33 & 0.00 & 11.11 & 0.00 & 6.67 \\
\hline yntactic node-switch & & 7.69 & 0.00 & 5.26 & 0.00 & 3.03 \\
\hline Semantic node-switch & & 0.00 & 14.29 & 0.00 & 0.00 & 0.00 \\
\hline Genre node-switch & & 0.00 & 0.00 & 0.00 & 0.00 & 8.33 \\
\hline Code-switch & & 0.00 & 0.00 & 0.00 & 0.00 & 16.67 \\
\hline Typing mistakes & & 1.28 & 2.18 & 2.94 & 2.20 & 3.04 \\
\hline Miscellaneous & & 14.61 & 11.17 & 14.21 & 6.30 & 15.38 \\
\hline Content & & 4.35 & 5.40 & 5.76 & 3.09 & 5.15 \\
\hline
\end{tabular}

Across the planning conditions, there is no fixed pattern between the languages for pausing after revising. In content in both languages, less pausing took place after revision in freewriting. In typing mistakes, more pausing occurred after revisions in the FL. The proportion of pauses after revision in miscellaneous is higher in the L1N than in the L1F, whereas in the FL, it is higher in the FLF. As shown above, in both languages and in both planning conditions, many miscellaneous revisions were of the subcategory others. In the FLN less pausing was needed after miscellaneous revisions due to the slower production and the more controlled processing.

\section{Discussion}

The analysis of the revisions shows that there are differences between $L 1$ and FL revising processes and that there are differences in these processes in and after planning by note-taking or by freewriting. For one, revising in the L1 took place less frequently than it did in the FL, and revising in freewriting took place less frequently than in note-taking. This demonstrates that the effect of fluency enhancement through freewriting was achieved best in the L1F, indicating that the writers were more confident in their writing processes in freewriting, and that this was fostered more in the L1 than in the FL. However, as was demonstrated in Breuer (2015a), this confidence was not justified in many aspects, and the higher speed in the production process demanded a more intense revising process during and after writing, which did not follow. The higher amount of revisions in the note-taking conditions, however, did not necessarily lead to more accurate texts either (see Stevenson, Schoonen and de Glopper 2006 for similar results). The revision rate could have been the result of the participants' higher usage of the L1 in the planning process and the missing stimulation of the FL formulation process in planning. This led to more difficulties in formulation and to word finding problems.

In the distribution of revisions in the different categories, one sees that, in all languages and in all planning conditions, the highest proportion of revisions took place in typing mistakes, 
followed by revisions of content and of miscellaneous. Thus, on the categorical level, the focus of the revisions is similar in all conditions, which means that the participants on this level were not flexible in their focus, or that they did not feel the need to alter their monitoring in the different conditions, which, however, would have been needed for better final texts.

In the L1F and in the SE, the proportion of revisions of typing mistakes was distinctly higher than in the note-taking conditions or in the FLF-condition. This is probably the consequence of the higher speed in which the participants were typing in these conditions (Breuer 2015a), which resulted in the writers' inability to adequately coordinate their motor executions to the higher demands that the speed of formulation placed on the executive processes (Kreiner 1996). The fact that the number and the percentage of revisions was highest in the L1F condition indicates that (a) here the formulation was most productive and led to the greatest difficulties with respect to motor executions; and (b) that the monitoring process was still able to spot the mismatches between the mental orthographic representations and the spelling found on screen, which led to a high amount of $r$-bursts. Additionally, in L1 academic writing the participants often used words which were not necessarily elements of their everyday vocabulary, since they tended to use more complex and/or foreign words. This corresponds to L1 academic genre conventions (Siepmann 2006), and to the automated motor executions intermeddled with accurate typing (Grabowski 2003).

Beside this, and beside word-initiated difficulties (e.g. foreign words), typing errors seem to have been rooted, in many cases, in an execution that was too slow for typing the planned formulation on time. For example, in mistakes like philopsohy, the letters that were typed instead of the correct ones anticipate the letters that are coming shortly afterwards. In other cases, the typing errors foreshadow a formulation that is already planned and stored in the articulatory buffer. For example, one participant had to revise, One the one hand, to on the one hand, when she had anticipated one in the intended execution of on. A further analysis of typing errors would be worthwhile, especially with respect to whether there are differences in the type of typing errors in the L1 and the FL. It might well be that in the L1 the collision of mental formulation and typing might be of more relevance in this error category because (mental) formulation works faster and more fluently, while in the FL more typing errors occur in cases when the FL letter combination is less common in the L1. Christensen (2004), for example, discovered that the orthographic-motor integration not only has an influence on execution, but also on creative aspects and on the structure of texts. In this way, the influence of L1 on FL writing might be a relevant factor also in execution.

The overall distribution of revisions also shows that the highest number of revisions in the FL was performed in error categories that were not influenced by the L1. Hardly any revisions of node-switches were conducted. The participants did not seem to have much awareness of their usage of the L1 in the FL writing process, although these formed by far the majority of errors in the final texts. The focus on content and typing mistakes is rather dangerous with respect to reader evaluation, because if readers do not possess knowledge of the writers' $L 1$, they will not be able to comprehend the texts completely in many cases, or they will at least encounter difficulties in trying to do so.

Content revision in the case of wording, sentence structure and text structure to a certain degree is, of course, interrelated with language. For example, the writers might have had difficulties in finding the 'perfect' word in the FL in expressing their thoughts; a revision of sentence structure made in order to clarify meaning would have been possibly unnecessary in German because of the declinations. However, with respect to node-switching, the participants either did not perceive them because of the high cognitive demands and the lowering of the blocking of the L1, or they concentrated more on other aspects (like typing mistakes and content), and because of this were not able to recognise and correct node-switches.

In contrast to the distribution of revisions in the main categories, in the subcategories of the relevant categories, there are differences in the $\mathrm{L} 1$ and the $\mathrm{FL}$ and in/after note-taking and in/after freewriting. The higher activation of thinking in writing during freewriting in the planning had an impact on the whole writing process. For example in content, the revision of information was either judged to be more important in these tasks, or the amount of new ideas that were generated during freewriting and afterwards in the formulation process were higher than in note- 
taking, and the participants had to add phrases and sentences (see Li 2007). The urge to find a better way of expressing thoughts is more highly developed and works more actively in the $\mathrm{L} 1$ than in the FL, which is the result of the better and the more broadly developed linguistic network in the L1, and also of the underlying differences in the monitoring of the writing processes in the L1 and the FL. However, it does not seem to have been a conscious decision to do so, but rather the effect of the higher cognitive demands in FL writing, and the less well developed linguistic network in the FL.

The planning methods also had an effect on revision: the different activation of linguistic structures had an impact on the focus of monitoring in the writing processes, but this effect was weaker in the FL than in the L1. The participants were better able to distribute their cognitive capacities more flexibly to the task conditions in the $L 1$, whereas they rather stuck to their familiar monitoring methods in the FL. That is, the participants would need more training in FL revising in order to be able to work according to the academic demands.

\section{Conclusion}

The analysis of the revising processes in $\mathrm{L} 1$ and $\mathrm{FL}$ writing in and after the different planning conditions shows that FL student writers use the same revision methods in all of the conditions on a broader level. A closer analysis shows that there are differences on a deeper level which are often the result of better linguistic competencies in the L1. However, this taking over of L1 revising methods and their adaptations did not have an overly positive effect on the written text. It is therefore necessary to make students explicitly aware of the differences of the needs for revision in $L 1$ and FL texts, and to show them methods for how to deal with these demands in order to enhance their texts efficiently.

For example, it is important to stress that the content being conveyed is the central focus of both $\mathrm{L} 1$ and $\mathrm{FL}$ text revisions. This means that (L1 and FL) students should first revise the content and the structure in which the content is offered. Only if these components are adequate should attention turn to the linguistic side of the text (academic genre characteristics, language). This cannot be done in one step since the cognitive demands in (FL) academic writing are so large that it is impossible to revise content, structure, style and language in parallel. When the linguistic revision is done in a separate step, the cognitive capacities have more resources to locate and 'fight down' L1 intrusion in the FL writing process. Otherwise the L1 will intervene, making the text complicated to read for $L 1$ readers who are often less flexible in understanding texts in their L1 written by FL writers, which contain severe linguistic errors (Hülmbauer 2009, Phillipson 2003).

For writing teachers, it is also important to keep these points in mind not only when teaching but also when giving feedback. Where they are L1 readers of FL texts, they should be aware of the danger of their lack of linguistic flexibility and try to see behind the linguistic façade, actively making efforts to find out what the writer wants to say and evaluating the content independently of the language quality in which it is executed. If students receive positive feedback on their content, they will be better motivated to revise their texts in other important areas, and to revise differently in the FL compared to the L1.

If FL writers and writing pedagogues are aware of these problems in revising and the possibilities of dealing with them, revising will help to make international exchanges more successful, less demanding and more fun, for the writers as well as for the readers. 


\section{References}

Alamargot, D. and Chanquoy, L. (2001) Through the Models of Writing. Dordrecht: Kluwer Academic Publishers

Becker, A. (2006) 'A Review of Writing Model Research Based on Cognitive Processes'. in Revision: History, Theory and Practice. ed. by Horning, A. and Becker, A. West Lafayette: Parlor Press, 25-49

Bereiter, C. and Scardamalia, M. (1983) 'Does learning to write have to be so difficult?' in Learning to Write: First Language, Second Language. ed. by Freedman, A., Pringle, I. and Yalden, J. London: Longman's International, 20-33

Bereiter, C. and Scardamalia, M. (1987) The Psychology of Written Composition. Hillsdale, New Jersey: Lawrence Erlbaum Associates

Bergh, H. and Rijlaarsdam, G. (1999) 'The Dynamics of Idea Generation During Writing: An Online Study'. in Knowing What to Write: Conceptual Processes in Text Production. ed. by Torrance, M. and Galbraith, D. Amsterdam: Amsterdam University Press, 99-120

Bergh, H. and Rijlaarsdam, G. (2007) 'The Dynamics of Idea Generation During Writing: An Online Study'. in Writing and Cognition: Research and Applications. ed. by Torrance, M., Waes, L. and Galbraith, D. Oxford, Amsterdam: Elsevier, 125-150

Breetvelt, I. Bergh, H. and Rijlaarsdam, G. (1994) 'Relations Between Writing Processes and Text Quality: When and How?' Cognition and Instruction 12 (2), 103-123

Breuer, E. O. (2015a) First Language versus Foreign Language: Fluency, Errors and Revision Processes in Foreign Langauge Academic Writing. Frankfurt a.M.: Peter Lang

Breuer, E. O. (2015b) 'Peer feedback in an FL context - who helps better: an L1 or an FL peer?' EATAW Conference on Academic Writing in Multiple Scholarly, Socio-Cultural, Instructional and Disciplinary Contexts: Challenges and Perspectives. held 15-17 June at Tallinn University of Technology

Britton, B. K. (1996) 'Rewriting: The Arts and Sciences of Improving Expository Instructional Text'. in The Science of Writing: Theories, Methods, Individual Differences, and Applications. ed. by Levy, C. M. and Ransdell, S. Mahwah: Lawrence Erlbaum Associates, 323-345

Chenoweth, N. A., and Hayes, J. R. (2001) 'Fluency in Writing: Generating Text in L1 and L2'. Written Communication 18 (1), 80-98

Elbow, P. (1973) Writing without Teachers. New York: Oxford University Press

Flower, L., and Hayes, J. R. (1980) 'The dynamics of composing: making plans and juggling constraints'. in Cognitive Processes in Writing: an Interdisciplinary Approach. ed. by Gregg, L. W. and Steinberg, E. R. Hillsdale, New Jersey: Lawrence Erlbaum Associates, 31-50

Flower, L., and Hayes, J. R. (1981) 'A Cognitive Process Theory of Writing'. College Composition and Communication 32 (4), 365-387

Galbraith, D. (1999) 'Writing as a Knowledge-Constituting Process'. in Knowing What to Write: Conceptual Processes in Text Production. ed. by Torrance, M. and Galbraith, D. Amsterdam: Amsterdam University Press, 139-159

Galbraith, D. (2009) 'Cognitive Models of Writing'. GFL Journal 2-3, 7-22 
Galtung, J. (1981) 'Structure, culture, and intellectual style: An essay comparing Saxonic, Teutonic, Gallic and Nipponic approaches'. Social Science Information 20 (6), 817-856

Hayes, J. R. (1996) 'A New Framework for Understanding Cognition and Affect in Writing'. in The Science of Writing: Theories, Methods, Individual Differences, and Applications. ed. by Levy, C. M. and Ransdell, S. Mahwah: Lawrence Erlbaum Associates, 1-27

Hayes, J. R. (2008) 'New Directions in Writing Theory'. in Handbook of Writing Research. ed. by MacArthur, C. A., Graham, S. and Fitzgerald, J. New York: The Guilford Press, 2840

Hayes, J. R. (2009) 'From Idea to Text'. in The SAGE Handbook of Writing Development. ed. by Beard, R., Myhill, D., Riley, J. and Nystrad, M. London: SAGE, 64-79

Hayes, J. R., Flower, L., Schriver, K., Stratman, J. F. and Carey, L. (1987) 'Cognitive processes in revision'. in Advances in Applied Psycholinguistics (Vol. 2): Reading, Writing and Language Processing. ed. by Rosenberg, S. New York: Cambridge University Press, 176-240

Hülmbauer, C. (2009) '“We don't take the right way. We just take the way that we think you will understand" - the shifting relationship between correctness and effectiveness in ELF'. in English as a Lingua Franca: Studies and Findings. ed. by Mauranen, A. and Ranta, E. Newcastle: Cambridge Scholars Publishing, 323-347

Kellogg, R. T. (1996) 'A Model of Working Memory in Writing'. in The Science of Writing. Theories, Methods, Individual Differences, and Applications. ed. by Levy, C. M. and Ransdell, S. Mahwah: Lawrence Erlbaum Associates, 57-71

Jackendoff, R. (2003) 'Précis of Foundations of Language: Brain, Meaning, Grammar, Evolution'. Behavioral and Brain Sciences 26 (6), 651-707

McCutchen, D. (2011) 'From novice to expert: Implications of language skills and writingrelevant knowledge for memory during the development of writing skill'. Journal of Writing Research 3 (1), 51-68

Peyer, A. (2003). 'Lehrpläne/Curricula'. in Didaktik der deutschen Sprache: Band 2. ed. by Bredel, U, Günther, H., Klotz, P., Ossner, J. and Siebert-Ott, G. Paderborn: Schöningh, $628-638$

Pritchard, R. J. andHoneycutt, R. L. (2008) 'The Process Approach to Writing Instruction: Examining Its Effectiveness'. in Handbook of Writing Research. ed. by MacArthur, C. A., Graham, S. and Fitzgerald, J. New York: The Guilford Press, 275-290

Phillips, W. A., and Baddeley, A. D. (1989) 'Learning and Memory'. in Cognitive Psychology. Research Directions in Cognitive Science: European Perspectives (Vol. 1). ed. by Baddeley, A. and Bernsen, N. O. Hove: Lawrence Erlbaum Associates, 61-83

Phillipson, R. (2003) English-Only Europe? Challenging Language Policy. London: Routledge

Rijlaarsdam, G., Couzijn, M. and Bergh, H. (2004) 'The study of revision as a writing process and as a learning-to-write process: Two prospective research agendas'. in Revision: Cognitive and instructional processes: Studies in writing (Vol. 13). ed. by Allal, L. K., Chanquoy, L. and Largy, P. Boston: Kluwer Academic Publishers, 189-207

Schübel, A. (2009) 'Von der Norm zur Vielfalt - Brauchen wir noch eine Substantivgroßschreibung?' in Sprachwandel und Entwicklungstendenzen als Themen im Deutschunterricht: fachliche Grundlagen - Unterrichtsanregungen Unterrichtsmaterialien. ed. by Siehr, K.-H. and Berner, E. Potsdam: Universitätsverlag, 25-46 
Stevenson, M., Schoonen, R. and Glopper, K. (2006) 'Revising in two languages: A multidimensional comparison of online writing revisions in L1 and FL'. Journal of Second Language Writing 15 (3), 201-233

\section{Abbreviations}

L1 First language

$\mathrm{FL} \quad$ Foreign language (learned and practised outside of the country in which the language is L1)

L2 Second language (learned and practised in the country in which the language is L1)

L1N Essay written in the L1 after having planned with the help of note-taking

FLN Essay written in the FL after having planned with the help of note-taking

L1F Essay written in the L1 after having planned with the help of freewriting

FLF Essay written in the FL after having planned with the help of freewriting SE Simple essay (text written in everyday style, taking on the view of the computer on the writing processes of the students)

$p$-burst Stretches of uninterrupted writing ended by pausing

$r$-burst Stretches of uninterrupted writing ended by revision 